\title{
Wind-driven monthly variations in transport and the flow field in the Faroe-Shetland Channel
}

\author{
Toby J. Sherwin, ${ }^{1}$ Sarah L. Hughes, ${ }^{2}$ William R. Turrell, ${ }^{2}$ Bogi Hansen ${ }^{3}$ \& Svein Østerhus ${ }^{4}$ \\ 1 Scottish Association of Marine Science, Dunstaffnage Marine Laboratory, Oban, Argyll, PA37 1QA, UK \\ 2 Fisheries Research Services, Marine Laboratory, 375 Victoria Road, Aberdeen, AB11 9DB, UK \\ 3 Faroese Fisheries Laboratory, Box 3051, FO-110, Torshavn, Faroe \\ 4 Geophysical Institute, University of Bergen, NO-5014, Bergen, Norway
}

\section{Keywords}

Meridional Overturning Circulation; North

Atlantic; currents; seasonal variability.

\section{Correspondence}

Scottish Association for Marine Science, Oban, Argyll, PA37 1QA, UK

E-mail: toby.sherwin@sams.ac.uk.

doi:10.1111/j.1751-8369.2007.00036.x

\begin{abstract}
The transport of water from the North Atlantic to the Nordic seas through the Faroe-Shetland Channel is analysed from a decade of conductivity, temperature and depth (CTD) and acoustic Doppler current profiler (ADCP) data. The long-term mean transport, integrated over the upper $500 \mathrm{~m}$, is $3.5 \pm 0.1 \mathrm{~Sv}$ $\left(1 \mathrm{~Sv}=10^{6} \mathrm{~m}^{3} \mathrm{~s}^{-1}\right)$, of which $2.1 \mathrm{~Sv}$ is barotropic flow and $1.4 \mathrm{~Sv}$ is baroclinic flow. Short-term variability leads to a standard deviation of ca. $2.2 \mathrm{~Sv}$ in 3-day averages of the ADCP-measured transport. The barotropic transport is located over the upper part of the slope region of the Shetland Shelf, but sometimes broadens over deeper water. There is a peak surface baroclinic transport above the foot of the slope, and a weak recirculation of Modified North Atlantic Water (MNAW), which enters from the north, on the Faroese side. In September, when isobars downwell on the eastern side, the strong transport (ca. 4 Sv) is barotropic and evenly distributed across the Shetland slope, and both recirculation of MNAW from the Faroe side and mesoscale activity are weak. In spring, the net transport is small (ca. 2.5 Sv), the MNAW recirculation is strong and mesoscale activity is relatively large. These seasonal variations appear to correlate with the local south-west wind stress, which may contribute to nearly half of the long-term transport in the channel.
\end{abstract}

The Faroe-Shetland Channel (FSC) is a deep channel in the northern north-east Atlantic that separates the Faroe and Shetland islands (Fig. 1). It is one of the main conduits of the northern limb of the North Atlantic Meridional Overturning Circulation (MOC), transporting nearly half the total oceanic heat and excess salt into the Nordic seas from the North Atlantic (Hansen \& Østerhus 2000). In addition, about one third of the total outflow from the north makes its way southward through the FSC on its way to the Faroe Bank Channel.

As with most major ocean currents the transport of water through the FSC varies naturally on many length and time scales.

- Millennial and centennial, embracing the whole Atlantic if not global circulation. Examples would be variations in circulation since the last glacial maximum (Rasmussen et al. 2002) up to and including the Mediaeval warm period and the subsequent Little Ice Age (Mayewski et al.
2004); these long-term cycles are probably caused by sunspot cycles and astronomical forcing.

- Decadal to interannual, on the scale of the North Atlantic (e.g., Olsen \& Schmith 2007). An example of forcing would be the North Atlantic Oscillation; such variability is a response of natural spatial and temporal scales of the ocean-atmosphere system.

- Seasonal, or monthly, on a regional scale. Ultimately resulting from the seasonal cycle of solar forcing, and the subject of this paper.

- Mesoscale motions on weekly timescales, within the FSC (e.g., Dooley \& Meincke 1981; Sherwin et al. 1999; Sherwin et al. 2006). This response to baroclinic instability is a major source of the measured transport variability in the FSC.

- High frequency. Freely propagating or topographically trapped internal and shelf waves (e.g., Gordon $\delta$ Huthnance 1987; Sherwin 1991; Hosegood et al. 2004). 


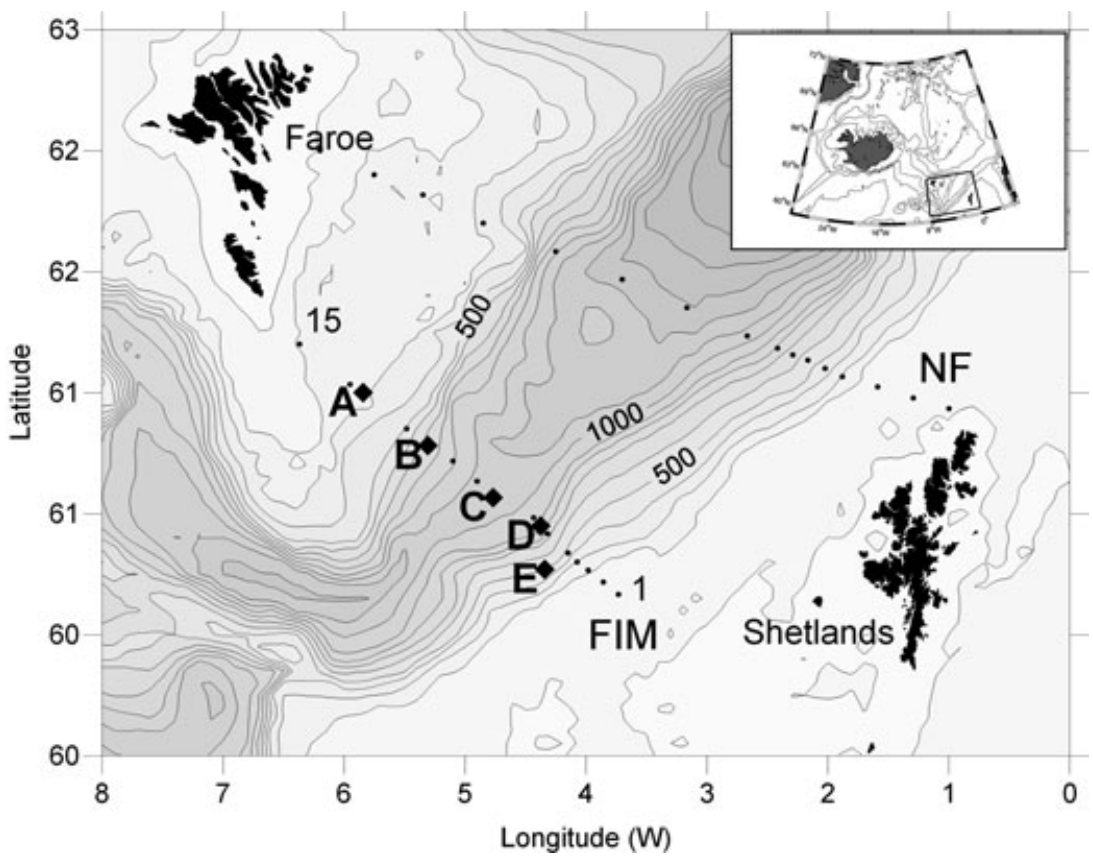

Fig. 1 Bathymetry of the Faroe-Shetland Channel at 100-m intervals. The acoustic Doppler current profiler (ADCP) positions are marked A-E. The stations along two conductivity, temperature and depth (CTD) sections are also shown, marked FIM (Fair Isle-Munken, with stations 1 and 15 indicated) and NF (Nolso-Flugga). The inset shows the location relative to the Greenland-Iceland-Scotland ridge.
This variability makes it difficult to measure the true transport directly, and a valid estimate can only emerge with long-term observations that are now becoming available and are discussed here.

Despite the existence of more than a century of conductivity, temperature and depth (CTD) observations, a proper appreciation of the size of the transport in the FSC has only been possible since long-term monitoring with recording current meters started there in the last decade. The comprehensive review of 'the Atlantic Current' in the FSC by Tait (1957) illustrates the problem that oceanographers in the first half of the 20th century encountered when determining its transport from geostrophic calculations. Using data from 69 sections taken between 1927 and 1952, Tait found that the transport through a line joining the northern points of the Faroes and Shetlands (the Nolso-Flugga line, Fig. 1) ranged over an order of magnitude, from 0.4 to $6.5 \mathrm{~Sv}$, with a mean value of $2.3 \mathrm{~Sv}\left(1 \mathrm{~Sv}=10^{6} \mathrm{~m}^{3} \mathrm{~s}^{-1}\right)$. We now know that although this range of transports is reasonable the mean value is too small because the method fails to include the barotropic component of the flow.

The importance of this component was demonstrated conclusively from comparisons of recording current meter and CTD observations made during the Overflow '73 expedition by Dooley \& Meincke (1981) along the Fair Isle-Munken (FIM) section (see Fig. 1). They found that rather than there being a simple north-eastward surface current across the whole of the FSC (as Tait had assumed) there was a recirculation, with Modified North Atlantic Water (MNAW; $S>35.1$, where $S$ is salinity) entering from the north on the Faroe side, to combine in part on the Shetland side with North Atlantic Water (NAW; $S>35.3$ ) entering from the south. This discovery forced a complete change in the strategy for monitoring transport in the FSC.

Since 1994 the Faroes Fisheries Laboratory (FFL) and Fisheries Research Services, Aberdeen (FRS) have jointly monitored the surface currents with up to five broadband acoustic Doppler current profilers (ADCPs) deployed across the channel along the FIM line (Fig. 1, Table 1). In a recent report based on the 11-year observation set described here, Hughes et al. (2006) suggested that the net flux of NAW crossing the Wyville Thomson Ridge is 4.0 Sv, with a decreasing trend on the order of $0.1 \mathrm{~Sv}$ per year.

Average temperature and salinity sections (Fig. 2) reveal the partition between NAW, which occupies the eastern side of the channel in the northward flowing slope current, and MNAW, which occupies the surface waters on the Faroe side. Beneath these water masses, Arctic Intermediate Water (AIW) and Modified East Icelandic Water recirculate in the FSC at depths of 400$600 \mathrm{~m}$, and below them lies cold southward flowing Norwegian Sea Deep Water (NSDW) (Hansen \& Østerhus 2000).

There is a significant density difference between the NAW and the MNAW, which results in a pronounced 
Table 1 Acoustic Doppler current profiler (ADCP) deployment data.

\begin{tabular}{|c|c|c|c|c|c|c|c|}
\hline \multirow[b]{2}{*}{ Mooring } & \multicolumn{2}{|c|}{ Average position } & \multirow[b]{2}{*}{$\begin{array}{l}\text { Depth of lowest } \\
\text { bin centre }(m)\end{array}$} & \multirow{2}{*}{$\begin{array}{l}\text { Depth } \\
\text { of water } \\
\text { (m) }\end{array}$} & \multirow[b]{2}{*}{$\begin{array}{l}\text { Distance }^{\mathrm{a}} \\
(\mathrm{km})\end{array}$} & \multirow[b]{2}{*}{$\begin{array}{l}\text { Principle current } \\
\text { direction }\left({ }^{\circ} \mathrm{T}\right)\end{array}$} & \multirow[b]{2}{*}{$\begin{array}{l}\text { Associated } \\
\text { width }(\mathrm{km})\end{array}$} \\
\hline & $\begin{array}{l}\text { Latitude } \\
\text { (N) }\end{array}$ & $\begin{array}{l}\text { Longitude } \\
\text { (W) }\end{array}$ & & & & & \\
\hline A & $61^{\circ} 0.00^{\prime}$ & $5^{\circ} 50.6^{\prime}$ & - & 295 & 52 & - & - \\
\hline B & $60^{\circ} 47.1^{\prime}$ & $5^{\circ} 18.1^{\prime}$ & 787.5 & 785 & 90 & 38 & 35.2 \\
\hline C & $60^{\circ} 35.8^{\prime}$ & $4^{\circ} 50.6^{\prime}$ & 787.5 & 1071 & 123 & 38 & 32.1 \\
\hline $\mathrm{D}$ & $60^{\circ} 27.1^{\prime}$ & $4^{\circ} 20.6^{\prime}$ & 762.5 & 752 & 154 & 67 & 24.0 \\
\hline$E$ & $60^{\circ} 20.0^{\prime}$ & $4^{\circ} 10.0^{\prime}$ & 437.5 & 421 & 171 & 54 & 18.0 \\
\hline
\end{tabular}

${ }^{a}$ Distance from $61^{\circ} 16.64^{\prime} \mathrm{N} 6^{\circ} 37.8^{\prime} \mathrm{W}$, about $1.2 \mathrm{~km}$ north-west of the formal Faroe end of the Fair Isle-Munken (FIM) line.

front that runs along the axis of the channel (see Fig. 3 and Sherwin et al. 2006). Drifters released in the channel tend to converge in the front where they travel rapidly north-eastward at speeds on the order of $70 \mathrm{~cm} \mathrm{~s}^{-1}$. The front is unstable and spawns meanders and large mesoscale eddies that travel along the Shetland slope (Sherwin et al. 1999). Other much colder eddies, with a strong AIW signal, have occasionally been observed in the FSC, particularly on the Nolso-Flugga line (Tait 1957), but also on the FIM line (Dooley \& Meincke 1981). These eddies seem to originate in the Iceland-Faroe front to the north and west of the FSC.

A description of the spatial scale of eddy kinetic energy (EKE) in the FSC (Sherwin et al. 2006) showed that EKE preferentially occurs in the deep water at fixed locations along the channel, and that the ADCP/CTD section happens to be distributed across the most energetic patch of EKE, with a peak in the centre of the channel (averaged over $200 \mathrm{~m}$ ) of ca. $350 \mathrm{~cm}^{2} \mathrm{~s}^{-2}$. This coincidence of FIM line with a high level of EKE introduces a short-term natural variability that compounds the problems of estimating long-term transport.

In the FSC the long-term transport can now be quoted with sufficient accuracy that it may be possible to see long-term trends (Hughes et al. 2006). Furthermore, analysis of the observations on a seasonal basis suggests that transports of both NAW and MNAW are weakest in June and strongest in early winter (Turrell et al. 2003). In the present paper we demonstrate that with a combination of continuous ADCP measurements and occasional CTD sections, monthly variations in the flow field can be resolved that provide further insight into the nature of the circulation and net transport in the channel.

\section{Observations}

\section{ADCP observations}

ADCPs were first deployed in the FSC, at positions A-E on the FIM line, as part of the Nordic World Ocean Circulation Experiment (NWOCE) programme in late
1994 (see Table 1 and Figs. 1, 2c, 4a), but it was not until the latter part of 1998 that a sustained period of observations across the channel commenced. Since then there has been fairly continuous measurement of the transport, although in June and September, when the instruments are briefly removed from the water for servicing, the data are slightly less comprehensive than for the rest of the year. Initially five instruments were deployed, but the transport on the Faroe Shelf at A is very small and the position was abandoned early on. Technical problems and fishing activity caused large data losses at position $\mathrm{E}$ in the early years, and data for 1995-1998 and for 20002001 have been supplemented with equivalent observations made from oil industry platforms located near to the 400-m isobath on the Shetland side.

The RD Instruments ADCP uses the return from an acoustic beam to determine currents at regular levels (or bins) through the water column. The instruments deployed along the FIM line are mounted on the seabed, or upward looking from a subsurface buoy, and measure currents in a series of bins that extend towards the sea surface. In order to give a fair representation of the streamlines of transport across the section, the principal axis of the currents were rotated to lie either (i) parallel to the mean direction of the channel, in the case of B and C where the mean flow has a strong cross-channel component, or (ii) along the mean transport path, in the case of $\mathrm{D}$ and $\mathrm{E}$ where local bathymetric steering dominates (see Table 1). More information on the processing of the ADCP data can be found in Appendix 1 .

\section{CTD observations}

CTD data were first collected in the FSC by the Fishery Board for Scotland in 1893 (Tait 1957), and until the 1960s the focus was on the Nolso-Flugga line. However, sampling along this line was intermittent. Since the deployment of the ADCPs in 1994 an intensive monitoring programme has been undertaken jointly by FFL and FRS along the FIM line with typically between 12 (FFL) and 15 (FRS) stations being occupied up to five times a 

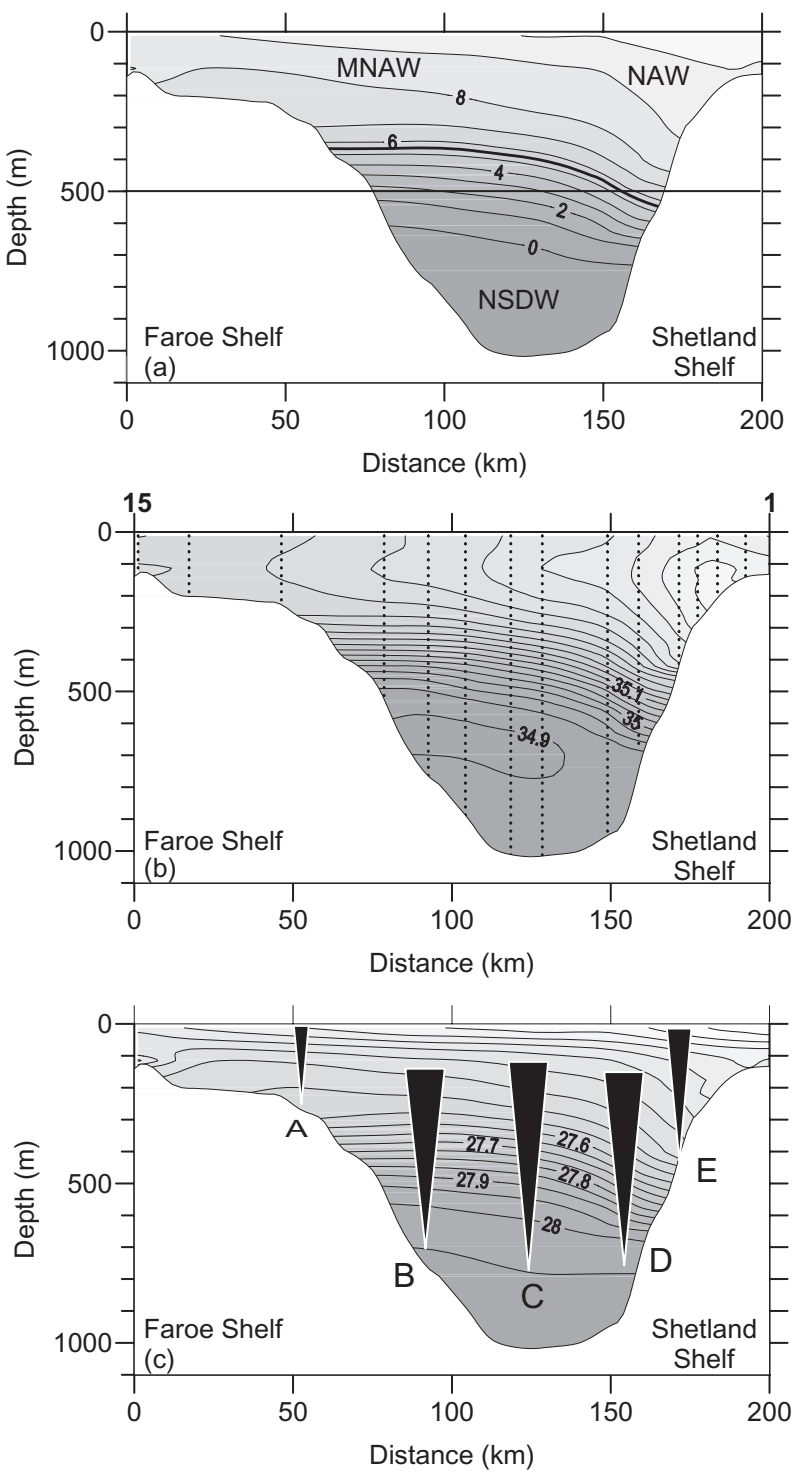

Fig. 2 (a) Mean temperature at $1{ }^{\circ} \mathrm{C}$ intervals. Approximate locations of different water masses are shown (NAW, North Atlantic Water; MNAW, Modified North Atlantic Water; NSDW, Norwegian Sea Deep Water). For reference the $5.5^{\circ} \mathrm{C}$ isotherm is emboldened, and the depth of the $500 \mathrm{~m}$ isopleth (the lower limit for $Q_{G 500}$ ) is shown. (b) Mean salinity at 0.25 intervals. (c) Mean density anomaly, $\sigma_{\mathrm{t}}$. The positions of the acoustic Doppler current profilers (ADCPs) and their acoustic range are shown.

year (Figs. 1,4). Salinity data are calibrated against in situ observations with an root mean square (RMS) error of typically 0.004 . From this observation programme a total of 66 sections (in which at least eight stations were occupied) have been selected. These data provide an intensive set of observations for comparison with the ADCP data, and earlier CTD observations have been ignored. Tests showed that the inclusion of the earlier data makes little

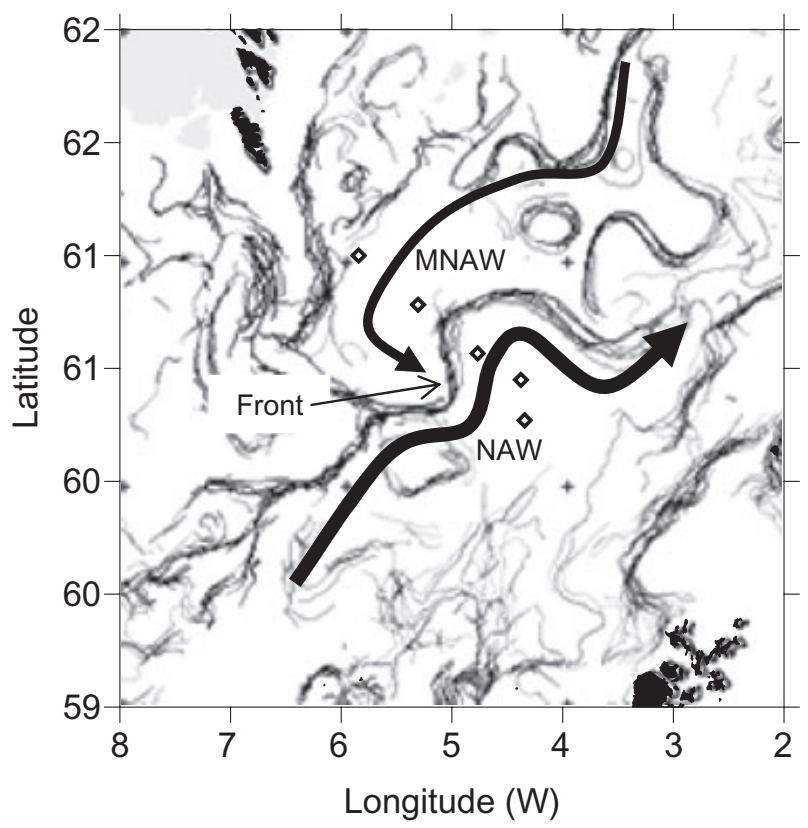

Fig. 3 The flow of surface waters between Faroe and Shetland during a week in May 1996 at a time of strong mesoscale activity. A composite of Advanced very High Resolution Radiometer (AVHRR) images have been digitally processed to identify the positions of fronts, which appear as stippled black lines. The main front in the Faroe-Shetland Channel (FSC) is indicated. Approximate tracks of the North Atlantic Water (NAW) slope current and recirculating Modified North Atlantic Water (MNAW) are shown. For reference the diamonds indicate the positions of the acoustic Doppler current profilers (ADCPS). AVHRR processing was performed by P. Miller, RSDAS, Plymouth, UK.

difference to the overall analysis, provided that the unusual observations of near-surface AIW water in August 1973, reported by Dooley \& Meincke (1981), are omitted.

\section{Transport calculations}

\section{Two definitions of transport}

The term 'transport', when applied to the oceanic context, is subject to interpretation, and is to some extent constrained by the method of measurement and the objectives of any analysis. In view of the different definitions that have been used elsewhere for flow across the Greenland-Scotland Ridge, we make the distinction clear.

\section{The simple transport of water through a section}

To calculate this it is only necessary to know the total current field (barotropic and baroclinic) that, in general, an array of ADCPs or recording current meters can measure adequately. No reference is made to the temperature or salinity of the water, but by making suitable 
Fig. 4 (a) Gannt chart of available acoustic Doppler current profiler (ADCP) data from each of the positions B-E. The bottom line (Total) shows occasions when all four ADCPs were functioning. (b) Number of conductivity, temperature and depth (CTD) sections by month. (c) Number of CTD sections by year.
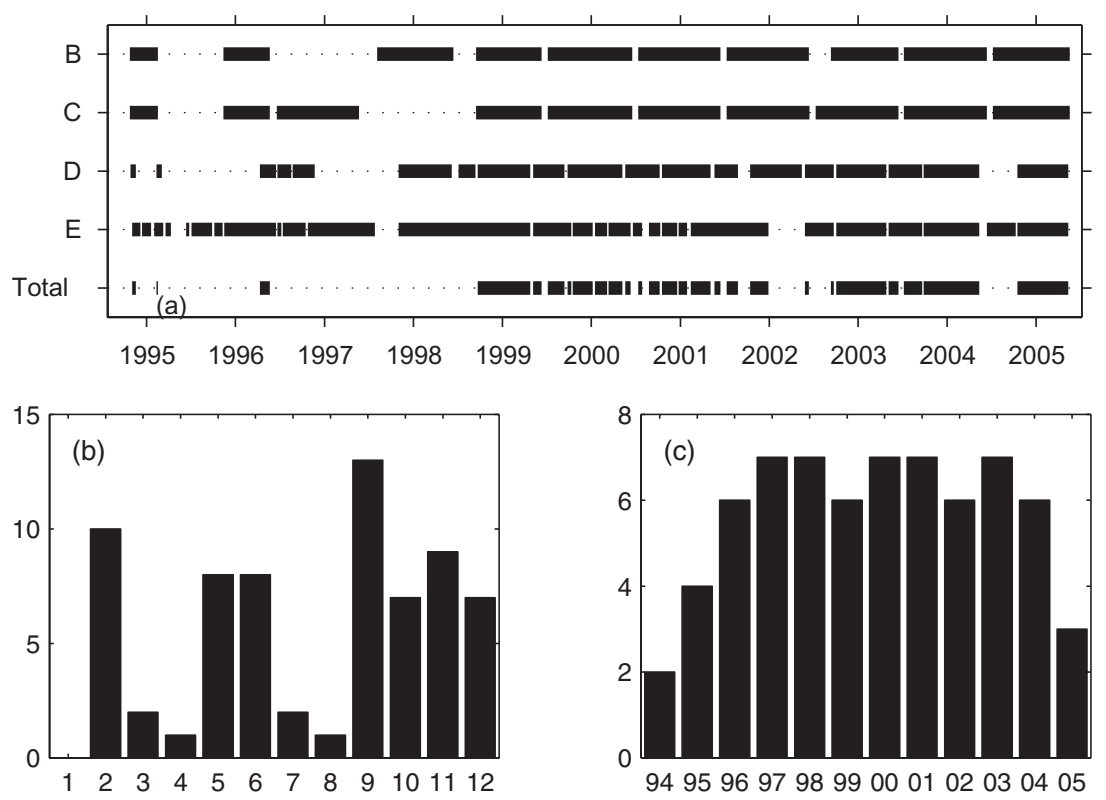

assumptions about their distribution it may be possible to determine appropriate heat and salt fluxes. This is the approach that will be adopted here.

The total transport of a water mass, identified by a specific value, or range, of temperature and salinity

This has been a particular detinition used on a section due north of Faroe, where warm Atlantic Water flowing northward across the Iceland-Faroe Ridge mingles with recirculating cold water from the north in the IcelandFaroe front to form MNAW (e.g., Hansen \& Østerhus 2000). It has also been used for transport in the FSC (e.g., Turrell et al. 1999, Hansen et al. 2000).

\section{ADCP-derived transport}

In the present discussion we use the ADCP data to investigate seasonal variations in the surface flow field, and for this purpose we chose the first definition of ocean transport. In order to facilitate the analysis we determine the 'transport density' ( $\Psi$, in units of Sv $\mathrm{m}^{-1}$ or $\mathrm{m}^{2} \mathrm{~s}^{-1}$, in the direction indicated in Table 1) at each ADCP position, $j$ (or, later, CTD station). We then use a typical finitedifference approach, associating site $j$ with a fixed width, $W_{j}$, from which the transport across the section, $Q$, can be derived. Thus,

$$
Q=\sum_{j} \Psi_{j} W_{j}
$$

where $j=\mathrm{B}, \mathrm{C}, \mathrm{D}, \mathrm{E}$ for the ADCPs or $j=1, \ldots, 15$ for the CTD sections.
The natural variability in the surface flow field means that its vertical and lateral extents are not always easy to define, particularly on the Shetland side. Several ways of computing the $\Psi_{j}$ were considered, before electing to use the simple procedure of integrating $u$, the along-channel current, between the surface and the 500-m isopleth, to coincide with the level of no mean motion at $\mathrm{D}$, where the largest transport occurs (Fig. 5). This is also the depth at which both $u$ and $\partial u / \partial z$, with $z$ being the vertical axis, are small at B and C (where flow reversals are common). Thus errors in the centre and towards the Faroese side of the channel are minimized. Transport density is assumed to be zero at A on the Faroe Shelf. At E on the Shetland Shelf edge the seabed (ca. $400 \mathrm{~m}$ ) is taken as the bottom boundary of the transport. The use of these rigid section boundaries should cause any recirculating MNAW (which is essentially an exchange process here) to vanish in any cross-section caclulation, but when the bottom water boundary rises sufficiently above $500 \mathrm{~m}$ the inclusion of deep southward Arctic outflow will reduce the calculated magnitude of the net northward transport (albeit by a small amount).

Thus a simple integration to $500 \mathrm{~m}$ is preferred to a more complicated algorithm, because it provides an objective Eulerian calculation that is compatible with both the ADCP measurements and the linear empirical orthogonal function analysis (EOFA) technique that will be used here (see below and Appendix 2). Also, this transport density can be readily compared with its geostrophic equivalent. The transport thus derived from (1) is labelled $Q_{500}$ in Table 2. It should be noted that $Q_{500}$ is effectively the 'total' transport because it comprises both baroclinic and barotropic components. 


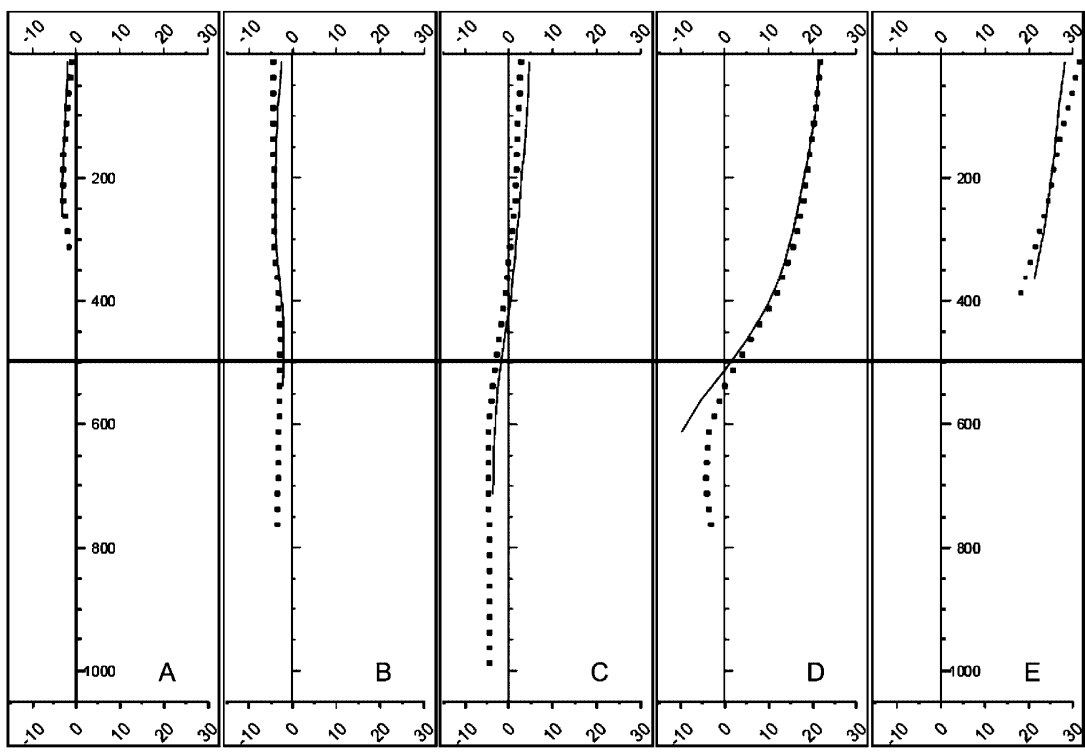

Fig. 5 Mean profiles of north-eastward velocity (dots) and the mean geostrophic shears (continuous lines) at each of positions A-E. The depth of the 500 isopleth (the lower limit for $Q_{500}$ ) is shown. Depth is in $\mathrm{m}$; speed in $\mathrm{cm} \mathrm{s}^{-1}$. Adapted from Hughes et al. (2006).
Table 2 Summary of transport between 1994 and 2005 in the FaroeShetland Channel (FSC) (in Sv).

\begin{tabular}{llllc}
\hline Source & $\langle\mathrm{Q}\rangle$ & SD of $Q$ & SE in $\langle Q\rangle$ & $\begin{array}{c}\text { No. of } \\
\text { observations }\end{array}$ \\
\hline $\begin{array}{l}\text { Total transport over } 500 \mathrm{~m} \\
\quad\end{array}$ & 3.5 & 2.2 & 0.06 & 595 \\
$\begin{array}{l}\left(Q_{500}\right) \\
\text { Total transport over water }\end{array}$ & 3.2 & 3.6 & - & $1785^{c}$ \\
$\quad$ column \\
$\quad$ NAW transporta, & 4.0 & 2.6 & - & $1785^{c}$ \\
Geostrophy $\left(Q_{G 500}\right)$ & 1.4 & 0.8 & 0.1 & 66 \\
Geostrophy $\left(Q_{G 5.5}\right)$ & 1.6 & 0.8 & 0.1 & 66 \\
Geostrophy $\left(Q_{G 535}\right)$ & 2.4 & 1.4 & 0.2 & 66 \\
\hline
\end{tabular}

${ }^{a}$ From Hughes et al. (2006).

${ }^{\mathrm{b}}$ Total transport of water that has crossed the Wyville Thomson Ridge.

${ }^{\mathrm{C}}$ Daily averages of 3-day low-pass filtered data.

A logical alternative to the above definitions is the whole section transport, which can be computed by extrapolating the current at the deepest observation bin down to the seabed at each ADCP to derive a full water column estimate of $\Psi$. This calculation includes the transport reversal resulting from the deep Arctic outflow and is included in Table 2 (from Hughes et al. 2006) because it provides a useful lower bound on estimates of the net northward transport.

A comment is required about the derivation of the associated widths (Table 1). In deep water $W_{j}$ was derived by using the standard space-centred difference between neighbouring ADCPs. The boundary on the Shetland side was chosen to be the $200-\mathrm{m}$ contour $(9.5 \mathrm{~km}$ south-east of east) following an inspection of the pattern of the mean drifter tracks in the FSC (see Sherwin et al. 2006). Errors associated with any variability of the position of this boundary have not been assessed. On the Faroe side the boundary was set at A where the net current is effectively zero.

In the section entitled 'Circulation in the FaroeShetland Channel' the discussion of mean transport is based on those occasions when data were recorded simultaneously at all of the four ADCPs, B-E. This restricts the total number of 3-day averages to 595, equivalent to about 60 months of independent observations. In the sections entitled 'Seasonal cycles in the circulation' monthly averages were calculated independently at each ADCP site before being summed into monthly mean transports.

\section{Geostrophic-derived transport}

The profile of the vertical shear normal to a CTD section, $\partial u / \partial z$, can be calculated from the density observations and the geostrophic balance (e.g., Apel 1987: 293):

$$
\frac{\partial u}{\partial z}=-\frac{g}{f \bar{\rho}} \frac{\partial \rho}{\partial y},
$$

where $f$ is the Coriolis frequency; $\partial \rho / \partial y$ is the horizontal gradient of density across the channel at depth $z$, and $\bar{\rho}$ is the mean density. In order to convert this shear profile into absolute geostrophic velocities, it is necessary to know the true velocity at at least one level. A level of no motion, $Z_{0}$, can then be defined and a transport density derived. As with the ADCPs, several definitions of transport have been investigated.

Provided $Z_{0}$ is well defined then geostrophic-derived transports are well suited to the requirements of either total or water mass transport calculation. However, if the 
barotropic current is strong then $Z_{0}$ may not exist and the geostrophic method may be invalid (see e.g., E in Fig. 5). Following the approach used to determine the ADCP transport, we have chosen a simple definition for $Z_{0}$ and then defined $\Psi$ as the integral of the geostrophic velocity to the surface. From the long-term ADCP observations (Fig. 5) we note that at C and D there is a level of no motion in the mean flow at about 400 and $500 \mathrm{~m}$, respectively. From comparison with the mean temperature section (Fig. 2a), $Z_{0}$ at these sites corresponds to the $5.5{ }^{\circ} \mathrm{C}$ isotherm. By contrast, at A and B there is very little variation with depth (i.e. the mean geostrophic current is weak) with a small southerly flow $\left(<3 \mathrm{~cm} \mathrm{~s}^{-1}\right)$ throughout the water column. Finally, at E a vertical shear of ca. $13 \mathrm{~cm} \mathrm{~s}^{-1}$ over $425 \mathrm{~m}$ is superimposed on a mean northward flow at the seabed of ca. $15 \mathrm{~cm} \mathrm{~s}^{-1}$. Thus the geostrophic transport can be realistically computed assuming that $u=0$ on either the $5.5^{\circ} \mathrm{C}$ isotherm or the seabed, as appropriate (this is $Q_{G 5.5}$ in Table 2).

However, for consistency with the ADCP transport calculations, it is preferable that the geostrophic $\Psi$ is integrated to $500 \mathrm{~m}$, rather than $Z_{0}$, to give $Q_{G 500}$, the baroclinic equivalent to $Q_{500}$ that includes a similar measure of the Arctic outflow. As Table 2 shows, the difference between the $Q_{G 5.5}$ and $Q_{G 500}$ is small, about $0.1 \mathrm{~Sv}$. For comparative purposes geostrophic transports have also been calculated with $Z_{0}$ coinciding with $S=35.0$ as used by Tait (1957) (Table 2, Fig. 2b).

The associated CTD widths were used to determine $Q$ from $\Psi$ in (1) using the centred method. The geostrophic currents are effectively nil at either end of the FIM section, so the total baroclinic transport is not sensitive to the definition of the associated widths at either boundary.

\section{Circulation in the Faroe-Shetland Channel}

\section{The total and baroclinic transports}

All the ADCP-derived estimates give fairly similar values: ranging from 3.2 Sv for the whole section transport to 4.0 Sv for the NAW transport, with $Q_{500}(3.5 \mathrm{~Sv})$ in the middle (Table 2 ). This range highlights the difficulty of deriving a precise transport estimate and indicates that (1) is a reasonable estimate of the net surface water transport in the FSC. By contrast, the geostrophic transports are significantly smaller with the 'best' estimate, $Q_{\text {G5.5 }}$ (1.6 Sv), being less than half of the ADCP 'total' transport estimates. The 35.0 isohaline is too deep for a satisfactory definition of $Z_{0}$, and leads to an estimate of $Q_{\mathrm{S35}}$ that is appropriate for neither the ADCP 'total' nor the geostrophic 'baroclinic' component of the flow.

The barotropic component of the surface transport, $Q_{B}$, is approximately defined as the difference between the total and the geostrophic transports, i.e. $Q_{\mathrm{B}}$ ca. $\left(Q_{500}-\right.$ $Q_{\mathrm{G} 500}$ ), whereas the baroclinic component, $Q_{\mathrm{G}}$, is ca. $Q_{G 500}$. Using values for $Q_{500}$ and $Q_{\mathrm{G} 500}$ from Table 2 shows that $Q_{\mathrm{B}}$ (2.1 Sv) is greater than $Q_{\mathrm{G}}(1.4 \mathrm{~Sv})$, but nevertheless they are of similar magnitude.

There is considerable variability in the 3-day transport estimates, and the signal-to-noise ratios for $Q_{500}$ and $Q_{6500}$ are low: 1.6 and 1.8, respectively. The autocorrelation function of $Q_{500}$ gives an integral timescale for independent observations of about 5.5 days, but as this timescale is not significantly greater than 3 days the error in the mean $(\varepsilon=\sigma / \sqrt{N}$, where $\sigma$ is the standard deviation and $N$ the number of 3-day observations, see Table 2) is ca. 0.1 Sv (or ca. $2.5 \%$ ).

\section{The across-channel transport structure}

In the subsequent discussion we will only use $Q_{500}$ (the total transport) and $Q_{G 500}$ (the baroclinic transport). From the long-term means it is apparent that $Q_{500}$ is concentrated over the Shetland Shelf edge and slope, whereas $Q_{\mathrm{G} 500}$ is strongest directly over the 600-m isobath, close to $\mathrm{D}$ (Fig. 6b). At C in the centre of the FSC there is a weak north-eastward transport but there is a much stronger south-eastward cross-channel transport (Fig. 6a). Most of the weak (negative) transport of MNAW at B recirculates in the channel and is balanced by additional transport on the Shetland side.

The differences in sampling strategy, combined with the logistic necessity to service the ADCPs at the same time as undertaking a CTD section, has resulted in a lack of coincident observations that makes it difficult to compare the CTD and ADCP datasets directly. In order to understand the variability in the flow in more detail it is useful to examine independent EOF analyses of the ADCP and geostrophic transport densities (see Appendix 2 for the method). Confidence that this approach is appropriate can be derived from the similarity in the shapes and magnitude (both relative and absolute) of mode-1 transport density derived from the two observation systems (Fig. 6c), although mode 1 only accounts for about $37 \%$ of the observed variability (Table 3 ).

The mode-1 ADCP transport density has a positive phase in which there is an increase in the transport on the

Table 3 Percentage variance accounted for by the largest empirical orthogonal function (EOF) modes.

\begin{tabular}{lll}
\hline Mode & ADCP $\left(Q_{500}\right)$ & Geostrophy $\left(Q_{\mathrm{G} 500}\right)$ \\
\hline 1 & 35 & 38 \\
2 & 21 & 24 \\
3 & 18 & 15 \\
4 & 10 & 10 \\
\hline
\end{tabular}



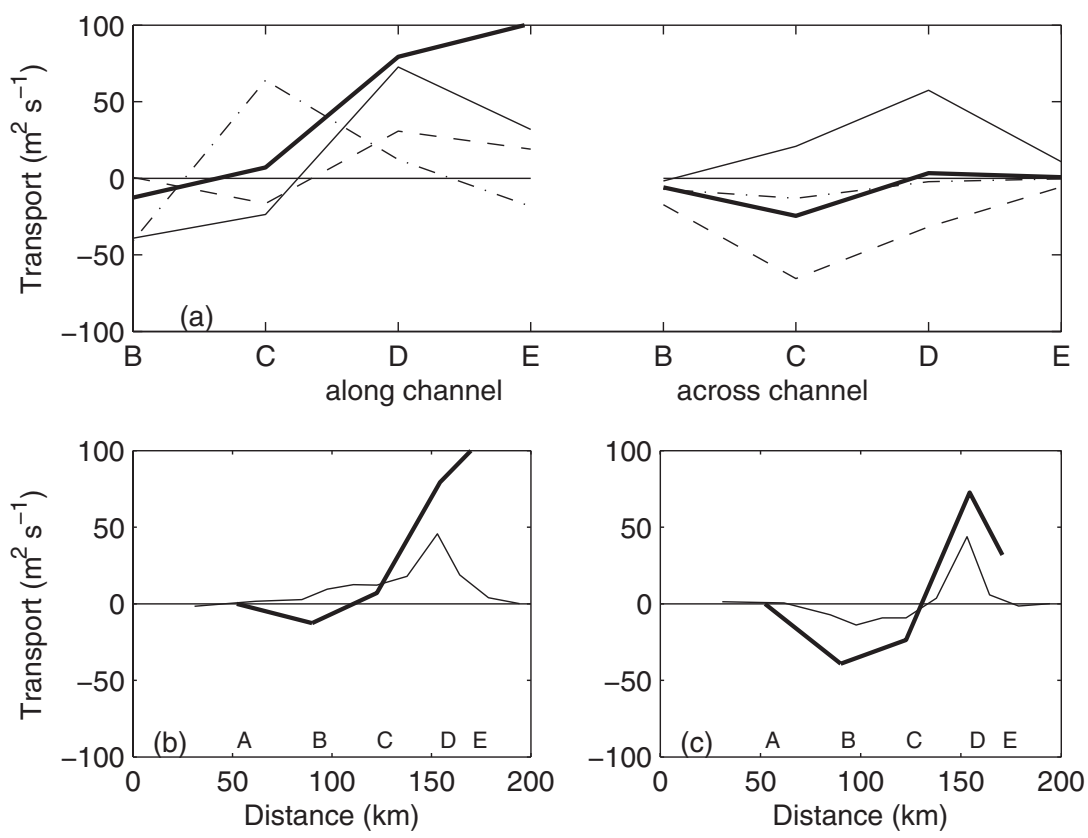

Fig. 6 (a) Eigenvectors of $\Psi$ for modes 1-4 at current meters B-E. Left-hand side, along channel (+ve to north-east); right-hand side, across channel (+ve to north-west). Thick line, mean; thin line, mode 1; dashed line, mode 2; dotdashed line, mode 3. Each mode $i$ is scaled so that its amplitude $\phi_{l}=1$ (see the Appendix 2 for further explanation). (b) Mean transport density. Thick line, total transport (integrates to $Q_{500}$ ); thin line, geostrophic transport (integrates to $Q_{G 500}$ ). The $x$-axis is measured from the Faroe end of the conductivity, temperature and depth (CTD) section (see note for Table 1). Mean density transport is extrapolated to zero at A. (c) Eigenvectors of the first barotropic and baroclinic modes plotted against distance from the Faroe end of the CTD section and scaled so that $\phi_{l}=1$. The positions of acoustic Doppler current profilers (ADCPs) A-E are shown in (b) and (c).
Shetland side, which is particularly noticeable at D where the current is deflected cyclonically (both the north-eastward and north-westward components are enhanced), with proportionally less of a response at $\mathrm{E}$ near the top of the Shetland slope (see Fig. 6a). At the same time the south-westward flow of MNAW increases on the Faroese side. The mode-1 baroclinic response (Fig. 6c) appears to mirror these effects, and it seems that much of the increase in transport seen at D in this mode is in fact baroclinic. (By the nature of [2] we are unable to determine baroclinic changes in the cross-channel flow from geostrophy.) When mode 1 is negative the net transport is reduced and tends to be more uniformly distributed across the channel, the recirculation of MNAW is small and there is a greatly reduced baroclinic transport on the Shetland side.

Mode 2 describes the main changes in the crosschannel transport of MNAW, particularly at C, which are generally independent of flow along the Shetland Shelf edge (Fig. 6a). When it is positive this transport is enhanced, and when it is negative there is little net transport across the channel.

\section{Two contrasting CTD sections}

Two CTD sections illustrate the density structure associated with these different flow regimes. On 12 September 1999 the geostrophic transport (1.7 Sv) was about 20\% greater than the mean $Q_{\mathrm{G} 5.5}$. The amplitudes of the first two modes were $\left[\phi_{1}, \phi_{2}\right]=[0.8,0.2]$, respectively, and the distribution of $\Psi$ across the section strongly resembles a combination of the mean transport with a positive mode 1 (Fig. 7). The isopycnal surfaces sloped down towards Shetland, and the baroclinic component peaked over the deeper part of the Shetland slope with a north-eastward surface current speed $>20 \mathrm{~cm} \mathrm{~s}^{-1}$ and a top-to-bottom velocity difference of $>60 \mathrm{~cm} \mathrm{~s}^{-1}$. (The mooring at D was being serviced at that time so the absolute velocity profile is not available.) Baroclinic currents on the Faroese side of the channel, where the isopycnal surfaces are flat, were small, and there was no evidence of mesoscale or eddy activity.

By contrast, on 15 June 1997 the geostrophic transport was weak $(0.33 \mathrm{~Sv})$, and the distribution of $\Psi$ across the section was made up of the mean transport with a negative mode 1 and large positive mode $2\left(\left[\phi_{1}, \phi_{2}\right]=[-0.8\right.$, 1.5], Fig. 8). It is thus likely (from the discussion of mode 2 above) that there was a strong cross-channel transport of MNAW occurring at this time, which may explain why the fastest baroclinic velocity was south-westward near the foot of the Faroese slope. The density and geostrophic sections suggest the presence of a mesoscale eddy near the Shetland Shelf.

\section{Seasonal cycles in the circulation}

\section{The monthly mean transports}

The monthly mean transports (Fig. 9) have been calculated independently as $\Psi_{j} W_{j}$ at each ADCP position using 

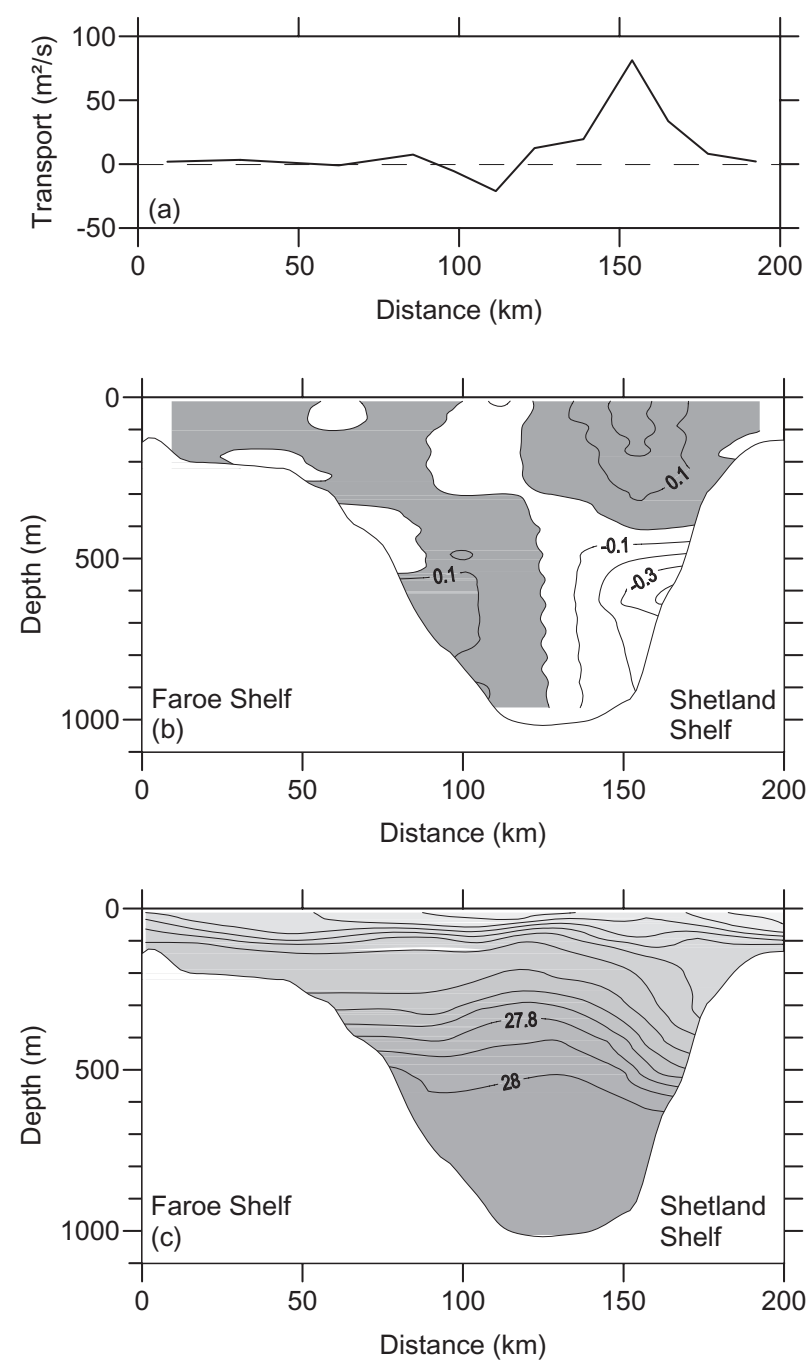

Fig. 7 (a) Transport density across the Faroe-Shetland Channel (FSC) on 12 Sept 1999 when $Q_{G 500}=1.7 \mathrm{~Sv}$ and $\left[\phi_{1}, \phi_{2}\right]=[0.84,0.17]$. (b) Geostrophic current in $\mathrm{m} \mathrm{s}^{-1}$ : north-eastward current is positive and shaded. (c) Density section, $\sigma_{\mathrm{t}}$ in $\mathrm{kg} \mathrm{m}^{-3}$.

all available observations in a particular month for that location (i.e. the requirement for concurrent observations across the channel is dropped). The total transport was then summed using (1). The error bars show the standard error in the mean of the individual current meters.

The total monthly mean transport of $Q_{500}$ varies from 2.3 Sv in April to 4.1 Sv in August, and has a standard deviation of $0.6 \mathrm{~Sv}$. The late spring/early summer minimum in the total transport appears to be associated with an increase in the southerly transport of MNAW at B. By contrast, the north-eastward barotropic flow of NAW on the Shetland side (E) is remarkably steady, and most of
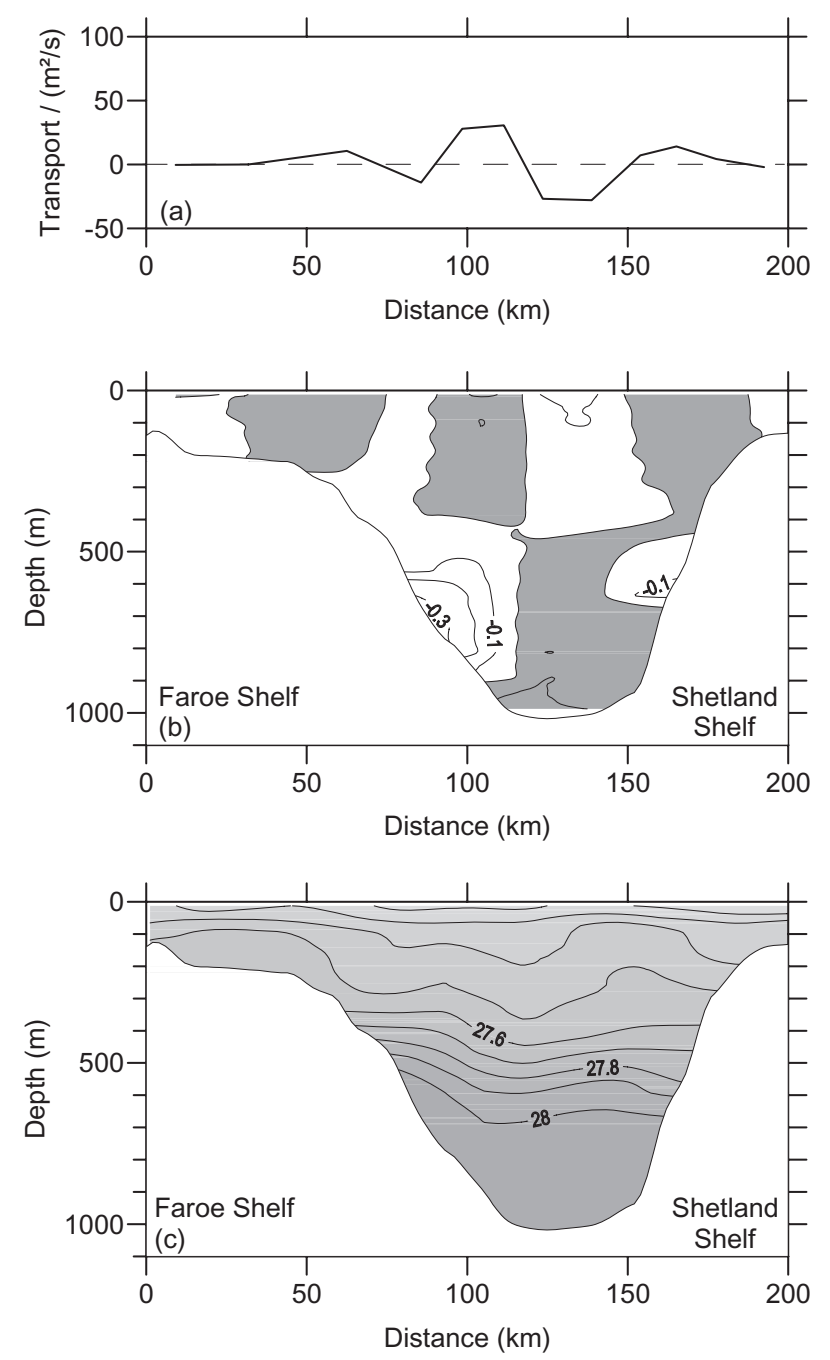

Fig. 8 (a) Transport density across the Faroe-Shetland Channel (FSC) on 15 June 1999 when $Q_{6500}=0.33 \mathrm{~Sv}$ and $\left[\phi_{1}, \phi_{2}\right]=[-0.80,1.46]$. (b) Geostrophic current in $\mathrm{m} \mathrm{s}^{-1}$ : north-eastward current is positive and shaded. (c) Density section, $\sigma_{\mathrm{t}}$ in $\mathrm{kg} \mathrm{m}^{-3}$.

the variability in $Q_{500}$ takes place offshore, particularly in the baroclinic component at D. To a large extent the transports either side of the channel (at B and D) are out of phase and reflect changes in the strength of the recirculating MNAW.

The surface velocity vectors provide further insight into these flow patterns. Throughout the winter months (from October to May, represented by December and March in Fig. 10) the mean flow is fairly persistent, with the strongest currents (ca. $20 \mathrm{~cm} \mathrm{~s}^{-1}$ ) over the shallow water at the top of the shelf, a slower mean speed offshore $\left(\mathrm{ca} .10 \mathrm{~cm} \mathrm{~s}^{-1}\right)$, and evidence of recirculation at $\mathrm{B}$ and C. By June, however, the north-eastward transport is 


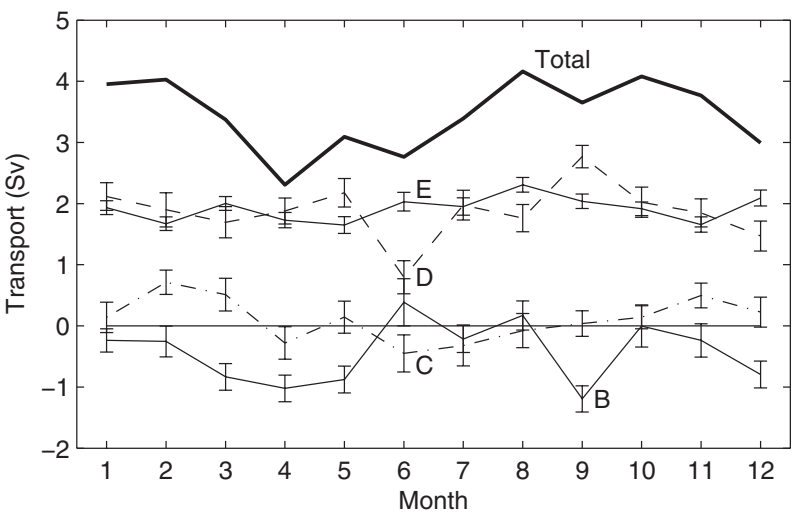

Fig. 9 Monthly variation in total transport in the upper $500 \mathrm{~m}$ of the Faroe-Shetland Channel (FSC) for $Q_{500}$ and for each current meter. Error bars are shown for the current meters. Positive values are north-eastward.
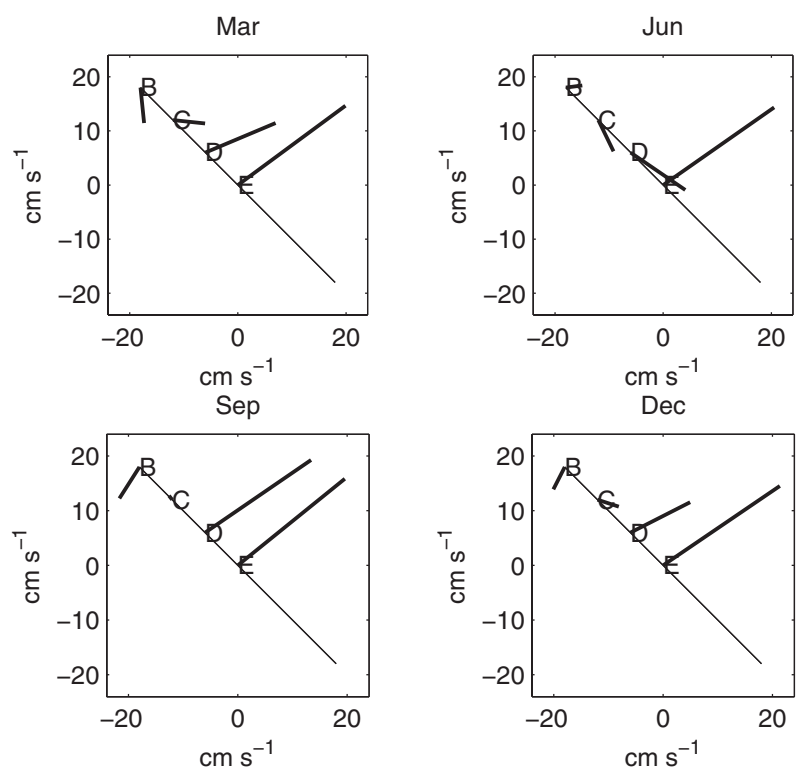

Fig. 10 Vector plots of mean surface currents for selected months.

confined to the Shetland Shelf edge, and to complement it there is considerable cross-channel flow (with speeds of up to $10 \mathrm{~cm} \mathrm{~s}^{-1}$ at D) towards the Shetland side. By and large the flow field returns to the winter regime after June, but in September there is another big change when a strong current picks up over the slope (with speeds approaching $20 \mathrm{~cm} \mathrm{~s}^{-1}$ at D).

\section{The monthly cycle of kinetic energy}

The kinetic energy of a moving body of water is $q^{2} / 2$, where $q$ is the speed (formed from both the along- and

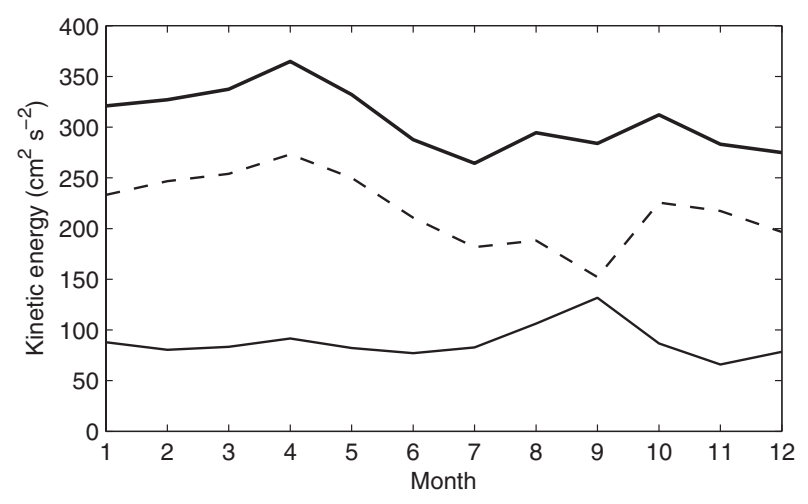

Fig. 11 Monthly variations in the overall mean kinetic energy (KE, thick line), eddy kinetic energy (EKE, dashed line) and MKE (thin line) in the top $500 \mathrm{~m}$.

across-channel velocities) and, by convention, we have dropped the implied density. For each month and at each ADCP, but averaged over the whole 11 -year record, the variance of $q$ at a particular level is

$$
\operatorname{var}(q)=\left\langle q^{2}\right\rangle-\bar{q}^{2}
$$

where $\left\langle q_{2}\right\rangle / 2=K E$ is the monthly mean $K E$ and $\bar{q}$ is the monthly mean speed. Thus $K E$ separates into two parts:

(i) the mean flow kinetic energy, $M K E=\bar{q}^{2} / 2$,

and

(ii) the eddy kinetic energy, $E K E=\operatorname{var}(q) / 2$.

EKE is normally taken to represent mesoscale activity.

The overall mean kinetic energy for the surface transport was then calculated by taking suitably weighted means of $K E$ at each of the ADCPs. (The weighting allowed for associated width and depth of water at each of the instruments, see Table 1.) A consideration of kinetic energy defined this way captures the vertical shear, but does not of itself explain the complete energy balance of the flow field (which also includes barotropic and baroclinic potential energy). However, these quantities are likely to be small and an investigation of the balance between the overall mean $M K E$ and $E K E$ provides insights into the seasonal variability of the flow field.

The overall mean KE remains fairly constant through the year, at about $310 \mathrm{~cm}^{2} \mathrm{~s}^{-2}$, but with slightly higher values at the beginning of the year (Fig. 11). By contrast the ratio of $M K E$ : EKE, which is of the order of 0.35 for most of the year, nearly trebles to 0.9 in September. At this time the EKE drops from a typical value of $250 \mathrm{~cm}^{2} \mathrm{~s}^{-2}$ to $180 \mathrm{~cm}^{2} \mathrm{~s}^{-2}$, whereas the $M K E$ increases from $90 \mathrm{~cm}^{2} \mathrm{~s}^{-2}$ to over $130 \mathrm{~cm}^{2} \mathrm{~s}^{-2}$. The drop in EKE in September, which coincides with the increase in trans- 
port, appears to be mainly caused by a decrease in mesoscale variability in the centre of the channel, particularly at D (see also Fig. 7b).

\section{Seasonal wind forcing}

A number of investigators have suggested that the variability in transport through the FSC is wind driven. By comparing historical geostrophic transport calculations with wind statistics Aas (1977) found that south-west wind forcing accounted for $20 \%$ of the mean transport. During Overflow '73 Dooley \& Meincke (1981) observed a brief current surge that they suggested may have been wind forced. A more thorough investigation of wind forcing was undertaken by Gordon \& Huthnance (1987) who looked at the generation of continental shelf waves by the wind on the shelf edge just north of Shetland. They found that long-period winds could elicit a quasi-steady barotropic current that flowed along the isobaths with speeds of $0.2-0.4 \mathrm{~m} \mathrm{~s}^{-1}$ for a peak wind stress of $1 \mathrm{~Pa}$.

Models of the European shelf have long demonstrated the role of wind forcing on residual circulation: for example Pingree \& Griffiths (1980) predicted that a net south-west stress of $0.16 \mathrm{~Pa}$ will force a current of order $10 \mathrm{~cm} \mathrm{~s}^{-1}$ along the neighbouring Shetland Shelf edge. Using a 3D primitive equation model of the FSC, Oey (1998) found that a peak wind from the southwest of $30 \mathrm{~m} \mathrm{~s}^{-1}$ could increase the background transport of $4 \mathrm{~Sv}$ to 7 or $8 \mathrm{~Sv}$, and that in general the annual cycle in wind forcing caused the transport to vary by about $1.5 \mathrm{~Sv}$.

The observations here indicate that the flow field in the FSC can be separated into three regimes (cf. Figs 10, 11):

(i) most of the year the transport is concentrated over the upper part of the slope region of the Shetland Shelf, and EKE is relatively large;

(ii) in spring recirculating MNAW on the Faroe side strengthens, mode 1 becomes negative and the net transport is weak; (iii) for a short time in September the transport over the Shetland slope is evenly distributed, barotropic and strong, mode 1 is positive and EKE levels are reduced.

Could the local wind field cause of these seasonal variations? There are several sources of historical wind velocities for the period 1994-2005, including the UK Met Office observations from Lerwick, Shetland, and the National Centers for Environmental Prediction and National Centre for Atmospheric Research (NCEP/NCAR) reanalysis (Kalnay et al. 1996) for two locations at $60^{\circ} \mathrm{N}$, $5^{\circ} \mathrm{W}$ (just north of the Wyville Thomson Ridge) and at $62.5^{\circ} \mathrm{N}, 2.5^{\circ} \mathrm{W}$ (at the northern end of the FSC). As the results for all three locations are similar we limit the discussion to the results from the southern NCEP/NCAR site because it is closest to the FIM line. Wind stress was calculated as

$$
\tau=\rho_{a} C_{a} W^{2},
$$

where $C_{a}=(0.61+0.0063 W) \times 10^{-3}, W$ is the wind speed and $\rho_{a}$ is the density of air, $1.15 \mathrm{~kg} \mathrm{~m}^{-3}$ (see e.g., Josey et al. 2002). If $W$ is in $\mathrm{m} \mathrm{s}^{-1}$ then $\tau$ is in Pascals.

Of particular interest here are the north-east and southwest components of wind stress, $\tau_{\mathrm{NE}}$ and $\tau_{\mathrm{SW}}$. This coordinate was identified by Aas (1977) as being the main wind direction, and as $\tau_{\mathrm{NE}}$ and $\tau_{\mathrm{Sw}}$ align with the channel they may cause upwelling and downwelling, respectively, on the Shetland slope. There is a pronounced seasonal signal in $\tau_{\mathrm{sw}}$ that is a minimum in high summer, but rises significantly in September. $\tau_{\mathrm{NE}}$ is generally weaker than its counterpart and lags it by about a month (Fig. 12a). Consequently, from April to June there is almost no net stress. By contrast there is a rapid jump in the net stress from the south-west $(\tau)$ between August and September when it increases from 0.035 to $0.075 \mathrm{~Pa}$. There is also a second large increase in $\tau$ between December and January.

Although neither $\tau_{\mathrm{sw}}$ nor $\tau_{\mathrm{NE}}$ alone correlate with the monthly variations in transport, $\tau$ is linearly proportional to $Q_{500}$ with a reasonably significant correlation coefficient $(R=0.53)$ and

$$
Q_{500}=2.0+20 \tau \mathrm{SV}
$$

Fig. 12 (a) Monthly variation in wind stress at $60^{\circ} \mathrm{N}, 5^{\circ} \mathrm{W}$. Thin plain line, from south-west, $\tau_{\mathrm{sw}}$; dashed line, from north-east, $\tau_{\mathrm{NE}}$; thick plain line, net stress, $\tau$. (b) $Q_{500}$ as a function of $\tau$. Individual months are identified. A least-squares fit shows $Q_{500}=2.0+20 \tau$ S v with $R=0.53$.
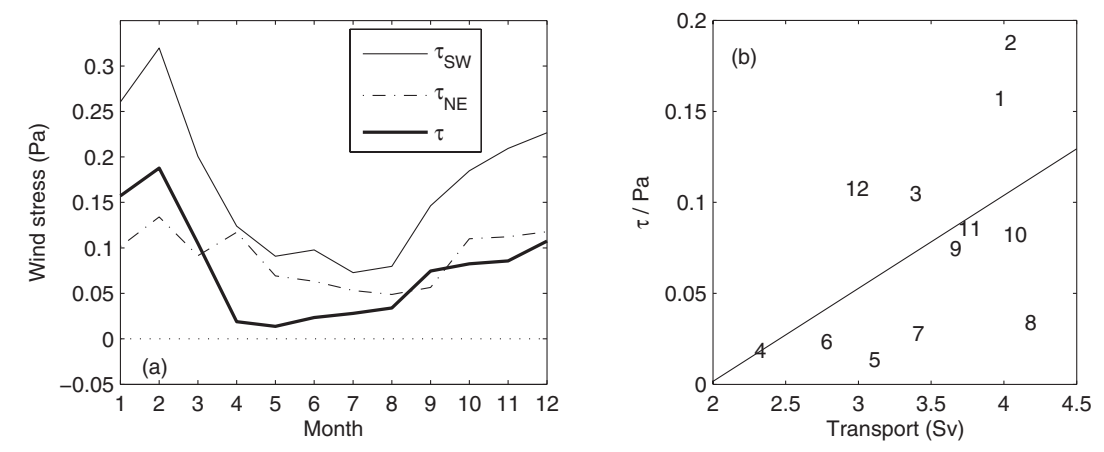
(Fig. 12b).( $R$ values at the northern end of the FSC and at Lerwick were similar: 0.66 and 0.53 , respectively.) Equation (5) indicates that the long-term mean of $Q_{500}(3.5 \mathrm{~Sv})$ is maintained by a mean $\tau$ of $0.075 \mathrm{~Pa}$. It thus appears that (a) nearly half of the mean transport $(1.5 \mathrm{~Sv})$ is driven by wind forcing, and (b) the net wind stress causes a seasonal variation in transport through the FIM section.

By considering the maximum winter steady state conditions it is possible to check the validity of (5). Following Huthnance (1984) we assume that in the steady state the slope current is determined by a balance between surface and bottom stresses such that

$$
\tau=\tau_{B}
$$

where $\tau_{\mathrm{B}}$ is the bottom stress given by quadratic friction based on the mean current,

$$
\tau_{B}=\rho C_{D} u|u| .
$$

Here, $\rho$ is the density of seawater $\left(\right.$ ca. $10^{3} \mathrm{~kg} \mathrm{~m}^{-3}$ ), $C_{\mathrm{D}}$ is a drag coefficient (ca. $2.5 \times 10^{-3}$ ) and $u$ is the velocity of the slope current. Combining (6) with (7) and taking, from Fig. 12, a maximum value of $\tau_{\max }=0.8 \mathrm{~Pa}$ gives $u$ ca. $0.2 \mathrm{~m} \mathrm{~s}^{-1}$. Figures 5 and 10 both show mean speeds of about $0.2 \mathrm{~m} \mathrm{~s}^{-1}$ at E, and Fig. 11 indicates that the maximum monthly wind stress effectively doubles the transport, so this is not an unrealistic estimate of the windforced current. If $\tau_{\max }$ drives a mode 1 barotropic current of the form suggested by Fig. 6 (i.e. roughly uniform at D and $\mathrm{E}$, and zero at $\mathrm{C}$ ), then the transport resulting from the wind stress, $Q_{\mathrm{w}}$, can be approximated by

$$
Q_{w}=\left(W_{D} h_{D}+W_{E} h_{E}\right) u ，
$$

where $W_{\mathrm{D}}, W_{\mathrm{E}}, h_{\mathrm{D}}$ and $h_{\mathrm{E}}$ are the associated widths and depths of water at D and C, respectively (see Table 2). Thus $\tau_{\max }$ implies a maximum wind-driven transport of $Q_{\mathrm{W}}$ ca. $20 \times 10^{6} u=4 \mathrm{~Sv}$. This rate is over twice that suggested by (5), but is good enough given the approximate way in which $\tau_{\mathrm{B}}$ has been estimated and (as Fig. 10 shows) the fact that the mean velocity at $\mathrm{D}$ is about half that at E. For further confirmation, the observed annual range of $1.9 \mathrm{~Sv}$ is only a little greater than the locally wind-forced range of 1.5 Sv modelled by Oey (1998).

The mean transport in this part of the MOC is likely to be driven over much larger spatial scales than are considered here, and forcing will include the north-south pressure gradient along the slope (e.g., Huthnance 1984) and/or ventilation of the Norwegian Seas (e.g., Hansen $\delta$ Østerhus 2000). In fact result (b) is not too surprising in view of the relationship between the variability in the Norwegian Atlantic Slope Current and the wind stress curl in the North Atlantic found by Skagseth (2004).

At this point we counsel a word of caution. Closer inspection of Figs. 9 and 12b shows a persistent and sig- nificant increase in transport between April and August (from ca. 2.3 Sv to ca. $4.2 \mathrm{~Sv}$ ) that takes place during the time of weak summer wind forcing. It is quite possible that other forces, such as a thermally derived pressure gradient caused by a meridional gradient in the seasonal heating cycle, are also involved.

Furthermore, the transport at $\mathrm{E}$ is largely invariant over the year, and most of the seasonal changes can be attributed to offshore transport, a fact that does not lie easily with the assumptions in (8). There may be a limit imposed on the barotropic transport at the shelf edge, caused by friction or some other dynamical consideration, which results in a spreading of the current onto the shelf and which is not captured by the present arrangement of current meters.

It is likely that the across-channel circulation is strongest in spring because $\tau$ is weakest at that time. Transport across the Iceland-Faroe Ridge is steady throughout the year (Hansen et al. 2003), so it is reasonable to assume that the production of MNAW there is roughly constant. It thus seems quite plausible that recirculating MNAW, which tends to flow anti-cyclonically around the Faroe Shelf into the FSC from the north (see e.g., Hansen \& Østerhus 2000; Sherwin et al. 2006), is only able to penetrate the channel extensively during spring. For the rest of the year it seems to be opposed by the net south-west wind stress that, although it may aid recirculation because it is upwelling favourable along the Faroe slope, will also tend to increase the intensity of the slope current by being downwelling favourable on the Shetland side.

\section{Conclusions}

In this paper we have used simple definitions of the north-easterly transport through the FSC above the 500-m isobath to determine the mean and monthly variability in the ADCP-derived total transport and the CTD-derived baroclinic transport. The main conclusions are:

(i) The long-term mean transport $\left(Q_{500}\right.$ ca. $\left.3.5 \mathrm{~Sv}\right)$ comprises approximately equal quantities of barotropic and baroclinic flow, with the former concentrated over the upper slope and on the shelf, and with the latter centred over the foot of the slope.

(ii) The precise lateral extent of the barotropic current on the Shetland Shelf is not well defined, and may give rise to unquantifiable errors in ADCP-derived transport estimates.

(iii) The overall mean EKE levels are relatively high (typically $310 \mathrm{~cm}^{2} \mathrm{~s}^{-2}$, averaged over $500 \mathrm{~m}$ ) and the standard deviation of 3-day averages of $Q_{500}$ are equally large $(2.2 \mathrm{~Sv})$. 
(iv) The minimum mean monthly transport (2.3 Sv) occurs in April, and the maximum (4.1 Sv) occurs in August.

(v) In late spring and early summer mode 1 tends to be in a negative phase, with relatively weak flow against the Shetland slope and relatively high levels of EKE (ca. $250 \mathrm{~cm}^{2} \mathrm{~s}^{-2}$ ) in the channel as MNAW penetrates the FSC from the north-west along the Faroese slope.

(vi) In early autumn, when the wind stress is downwelling favourable on the Shetland side, mode 1 is positive with a strong flow against the slope and relatively weak levels of EKE $\left(180 \mathrm{~cm}^{2} \mathrm{~s}^{-2}\right)$.

(vii) It is possible that nearly half of the north-east transport of water through the FSC is attributable to the wind stress, with the rest assumed to be driven by a northsouth pressure gradient.

These observations thus provide further evidence that there are systematic changes in the seasonal patterns of transport of water through the FSC that appear to be wind influenced. The variations in the relationship between the flows of NAW and MNAW may provide preconditioning for the generation of the baroclinic instabilities that are observed in the FSC.

\section{Acknowledgements}

This work was part of MOEN, a research project supported by the European Commission under the Fifth Framework Programme (contract no. EVK2-CT-2002-00141). Figure 1 is used courtesy of Peter Miller, RSDAS, Plymouth, UK (Miller in press). The NCEP Reanalysis data were provided by the NOAA/OAR/ESRL PSD, Boulder, Colorado, USA, from their website at http://www.cdc. noaa.gov. We are also very grateful for some perceptive comments to an earlier draft by an anonymous referee.

\section{References}

Aas E. 1977. The mean seasonal variation in the transport of Atlantic Water through the Faroe-Shetland Channel. Department of Geophysics Report 28.

Apel J. R. 1987. Principles of ocean physics. London: Academic Press.

Aubrey D. G. \& Emery K. O. 1983. Eigenanalysis of recent United States sea levels. Continental Shelf Research 2, 2133.

Dooley H. D. \& Meincke J. 1981. Circulation and water masses in the Faroese Channels during Overflow '73. Deutsche Hydrographische Zeitschrift 34, 41-54.

Godin G. 1968. The analysis of tides. Liverpool: Liverpool University Press.

Gordon R. L. \& Huthnance J. M. 1987. Storm-driven continental shelf waves over the Scottish continental shelf. Continental Shelf Research 7, 1015-1048.
Hansen B., Jónsson S., Turrell W. R. \& Østerhus S. 2000. Seasonal variations in the Atlantic Water inflow to the Nordic seas. Paper presented at the ICES Annual Science Conference, Bruges, CM2000/L:03.

Hansen B. \& Østerhus S. 2000. North Atlantic-Nordic seas exchanges. Progress in Oceanography 45, 109-208.

Hansen B., Østerhus S., Hátún H., Kristiansen R. \& Larsen K. M. H. 2003. The Iceland-Faroe inflow of Atlantic Water to the Nordic seas. Progress in Oceanography 59, 443-474.

Hosegood P., Bonnin J. \& van Haren H. 2004. Solibore-induced sediment resuspension in the Faeroe-Shetland Channel. Geophysical Research Letters 31(9), L09301, 10.1029/ 2004 GL019544.

Hughes S. L., Turrell W. R., Hansen B. \& Østerhus S. 2004. Long term measurements of currents in the Faroe Shetland Channel (1994-2002). FRS Collaborative Report no 01/05. Aberdeen: Fisheries Research Services.

Hughes S. L., Turrell W. R., Hansen B. \& Østerhus S. 2006. Fluxes of Atlantic Water (volume, heat and salt) in the FäroeShetland Channel calculated from a decade of acoustic Doppler current profiler data (1994-2005). FRS Collaborative Report 01/06. Aberdeen: Fisheries Research Services.

Huthnance J. M. 1984. Slope currents and “JEBAR". Journal of Physical Oceanography 14, 795-810.

Josey S. A., Kent E. C. \& Taylor P. K. 2002. Wind stress forcing of the ocean in the SOC climatology: comparisons with the NCEP-NCAR, ECMWF, UWM/COADS, and Hellerman and Rosenstein datasets. Journal of Physical Oceanography 32, 1993-2019.

Kalnay E., Kanamitsu M., Kistler R., Collins W., Deaven D., Gandin L., Iredall M., Saha S., White G., Woollwn J., Zhu Y., Chelliah M., Ebisuzaki W., Higgins W., Janowiak J., Mo K., Ropelewski C., Wang J., Leetmaa A., Reynolds R., Jenne R. \& Joseph D. 1996. The NCEP/NCAR 40-year reanalysis project. Bulletin of the American Meteorological Society 77, 437470 .

Mayewski P. A., Rohling E. E., Curt Stager J., Karlen W., Maasch K. A., David Meeker L., Meyerson E. A., Gasse F., van Kreveld S., Holmgren K., Lee-Thorp J., Rosqvist G., Rack F., Staubwasser M., Schneider R. R. \& Steig E. J. 2004. Holocene climate variability. Quaternary Research 62, 243-255.

Miller P.I. in press. Composite front maps for improved visibility of dynamic sea-surface features on cloudy SeaWiFS and AVHRR data. Journal of Marine Systems.

Oey L. Y. 1998. Subtidal energetics in the Faroe-Shetland Channel: coarse-grid model experiment. Journal of Geophysical Research-Oceans 103 (C6), 12689-12708.

Olsen S. M. \& Schmith T. 2007. North Atlantic-Arctic Mediterranean exchanges in an ensemble hindcast experiment. Journal of Geophysical Research-Oceans 112 (C4), C04011, 10.1029/2006JC003719.

Pingree R. D. \& Griffiths D. K. 1980. Currents driven by a steady uniform wind stress on the shelf seas around the British Isles. Oceanologica Acta 3, 227-236.

Rasmussen T. L., Backstrom D., Heinemeier J., KlitgaardKristensen D., Knutz P. C., Kuijpers A., Lassen S., Thomsen E., Troelstra S. R. \& van Weering T. C. E. 2002. The FaroeShetland Gateway: Late Quaternary water mass exchange 
between the Nordic seas and the northeastern Atlantic. Marine Geology 188, 165-192.

Sherwin T. 1991. Evidence of a deep internal tide in the FaroeShetland Channel. In B.B. Parker (ed.): Tidal hydrodynamics. Pp. 469-488. New York: John Wiley.

Sherwin T. J., Turrell W. R., Jeans D. R. G. \& Dye S. 1999. Eddies and a mesoscale deflection of the slope current in the Faroe-Shetland Channel. Deep-Sea Research I 46, 415-438.

Sherwin T. J., Williams M. O., Turrell W. R., Hughes S. L. \& Miller P. I. 2006. A description and analysis of mesoscale variability in the Faroe-Shetland Channel. Journal of Geophysical Research-Oceans 111 (C3), C03003, 10.1029/ 2005JC002867.

Skagseth Ø. 2004. Monthly to annual variability of the Norwegian Atlantic slope current: connection between the northern North Atlantic and the Norwegian Sea. Deep Sea Research I 51, 349-366.

Tait J. B. 1957. Hydrography of the Faroe-Shetland Channel 19271952. Marine Research 2. Edinburgh: Her Majesty's Stationery Office.

Turrell W. R., Hansen B., Hughes S. L. \& Østerhus S. 2003. Hydrographic variability during the decade of the 1990s in the northeast Atlantic and southern Norwegian Sea. ICES Marine Science Symposia 219, 111-120.

Turrell W. R., Hansen B., Østerhus S., Hughes S. L., Ewart K. \& Hamilton J. 1999. Direct observations of inflow to the Nordic seas through the Faroe Shetland Channel. Paper presented at ICES Annual Science Conference, Stockholm, CM 1999/ $\mathrm{L}: 01$.

\section{Appendix 1. ADCP data processing}

\section{Introduction}

An ADCP transmits regular pulses of sound ('pings') and listens to the Doppler shift of echoes that are reflected in the water column by small, mostly biological, particles. By using a method of gating the returning echoes, digital processing and an arrangement of four transceivers that direct acoustic beams at an incline to the vertical, it is able to compute water velocity at a large number of different levels, or bins, above the instrument. Beam interference means that observations are not possible near a reflecting boundary, and transmission time considerations place a similar limitation near the instrument. In addition, an absence of scatterers may, on occasion, limit the total range (normally about $500 \mathrm{~m}$ ).

Between 1994 and 2005 current velocities were measured with a mix of $75-\mathrm{kHz}$ and $150-\mathrm{kHz}$ RD Instruments (RDI) broadband ADCPs, deployed at five standard mooring sites (A-E) on the FIM line (Fig. 1), although for operational purposes the mooring at $\mathrm{E}$ was displaced about $10 \mathrm{~km}$ to the south-east. The initial deployments were undertaken as part of the Nordic WOCE (NWOCE) project, with later deployments being part of the EU-funded VEINS and MAIA projects. Since 2003 two of the moorings, situated on the Shetland Shelf edge of the channel, have been funded by the Scottish Executive under the ROAME AE1 190. Observations on the Shetland side were supplemented at times with ADCP data collected from oil platforms and provided by the North West Approaches Group (NWAG), a consortium of oil companies.

FFL service the three moorings on the north-western side of the channel. Moorings on its south-eastern side are serviced by FRS and, where used, by NWAG's contractors, Fugro GEOS. Each organization deployed and recovered its own instruments, and was responsible for data processing through the preliminary quality control stages.

Further information about the ADCP deployments and typical mooring designs for each site are described in Hughes et al. (2004, 2006). Here we give a brief overview of the quality control process, which is similar to an earlier description given in Turrell et al. (1999).

\section{Preliminary data interpolation}

The first stage of quality control was performed within the ADCP, where data from each ping were automatically rejected if they failed to meet preset quality standards. In addition it was necessary to apply further quality control procedures.

Data collected in beam coordinates were converted to earth coordinates, and a magnetic correction was applied to the heading and current direction data. Erroneous data at the extremes of the vertical measurement range and at the start and end of each deployment were removed. The early NWOCE records had single-ping data, and ensembles were rejected if the 'correlation' values for each ping were low or if the 'error velocity' was high. Obvious spikes remaining in the records were removed manually.

All data from a particular level (or bin) were rejected when the overall data return in that bin fell below $50 \%$ of the available records in that deployment, and any records containing gaps greater than $6 \mathrm{~h}$ in all bins were split into separate time series. In general, mooring knock-down was of the order of 1-2 m, and could be ignored, but on occasion large currents could tilt an instrument and set it down by over $20 \mathrm{~m}$. At such times the data have been ignored. In addition, the NWAG records required careful removal of observations made during rig-thruster activity, or were biased by acoustic reflections from risers attached to the drilling rig. These data were also corrected for compass offset caused by the proximity of the rig structure.

At the end of quality control the datasets contained gaps where ensembles had been rejected. Gaps shorter than $6 \mathrm{~h}$ were filled with linear interpolation from before and after the gap, at each bin depth. Some of the records 
contained individual bins with gaps of longer than $6 \mathrm{~h}$, mostly resulting from the loss of data near the surface during periods of low scatterer density. These gaps were filled by copying data from the next available valid bin below, which prepared the records for filtering. At the end of this processing stage, the data consisted of some 60 or so separate quality controlled records, interpolated to fill small gaps in time, but remaining at the original sampling rate, bin depths and bin lengths. These data were then passed to the secondary stage of processing.

\section{Secondary ADCP data processing}

In the next stage, velocity data from individual ADCP deployments at each site were amalgamated to create five concurrent datasets, one for each mooring site, each 10years long and of standard record ( $1 \mathrm{~h}$ ) and depth $(25 \mathrm{~m})$ intervals using the following procedures.

Hourly averages of each dataset, centred on the hour (e.g., the $0900 \mathrm{~h}$ record, represents the period from $0830 \mathrm{~h}$ to $0930 \mathrm{~h}$ ), were produced and linearly interpolated onto a regular vertical grid with $25-\mathrm{m}$ spacing, with the uppermost bin centred at a depth of $12.5 \mathrm{~m}$. At this stage individual records were not extrapolated above the highest, or below the lowest, valid bin. At each of the five sites, all available datasets were then merged to create single files containing hourly mean 25-m bin northward and eastward velocities. Missing data were represented by a marker, and the time series were smoothed with a 3-day low-pass filter (Godin 1968), which removed both the stationary barotropic and fluctuating baroclinic components of the tidal signal.

As the ADCP cannot measure currents close to the surface, velocities at the top were extended to the surface using the vertical shear from an individual profile. To avoid overestimation of the near-surface maxima the upper shear threshold was set to between 0.08 and $0.14 \mathrm{~cm} \mathrm{~s}^{-1} \mathrm{~m}^{-1}$, depending on the site. Only $0.1 \%$ of all the records exceeded this limit. It was found that during winter the echo amplitude near the surface had a clear daily signal that could result in a loss in observations in the upper $200 \mathrm{~m}$ at midday. However, as this effect gave rise to a 24-h signal in the data it should not cause a significant problem for the present analysis because we only consider 3-day filtered data.

At some sites datasets were amalgamated. At C, data from conventional current meters (Aanderaa RCM7s) located beneath the ADCP were added. At D and E, when records from the FRS and a neighbouring NWAG instrument coincided, the instrument with the greatest depth range of valid data was selected. This generally resulted in FRS records being chosen in preference to NWAG records. In general NWAG data were used at E from 1995 to 1997 inclusive, and for 2000 and 2001 inclusive. NWAG data have been substituted for D on a couple of short occasions prior to 2000. Checks have been conducted to confirm that the use of these substitute data has not created any bias or trends in the results.

\section{Instrument continuity}

Preliminary results revealed that transports at A were negligible, and in 2001 the site was abandoned. Mooring sites $\mathrm{B}$ and $\mathrm{C}$ have been populated by between eight and nine continuous, full-year deployments, augmented by two shorter deployments at C by Aanderaa current measurements. During one deployment at C (August 1997June 1998) the ADCP was inadvertently deployed upside down. At both B and C, single deployments (B, August 1997-June 1998; C, July 1999-June 2000) had limited depth ranges because of instrument malfunction.

Deployments at D and E were most problematic, particularly prior to 2002. Despite six-monthly servicing intervals, equipment was sometimes lost to intense fishing activity, and sometimes to an unusually aggressive corrosion of the stainless steel mooring components. The imposition of an oil development area meant that the position of $\mathrm{E}$ had to be moved. However, drilling rigs within the development area often have rig-mounted downward-looking ADCPs fitted, which have provided gap-filling data, particularly at E.

Before 1999, there are limited periods when data were available at sites B-E simultaneously. The situation has improved since then, and in total there are 1785 days when data were available at all four sites simultaneously.

\section{Appendix 2. EOF analysis}

For completeness, we provide a formal description of EOFA, sometimes called principal component analysis. EOFA is a method of objectively estimating the most likely linear relationships of a number of different time series based on an empirical analysis of the original dataset. In the present case the relationships are chosen to be the eigenvectors of a covariance matrix formed from the time series. This has the property that the first eigenvector (mode 1) removes the greatest level of variance from the set of time series, and mode 2 removes the next greatest level etc.

Following Aubrey \& Emery (1983) we start with a set of $J$ time series, each containing $N$ elements:

$$
\boldsymbol{U}=\left[\begin{array}{ccccc}
u_{11} & \ldots & u_{1 n} & \ldots & u_{1 N} \\
\vdots & & & & \vdots \\
u_{j 1} & \ldots & u_{j n} & \ldots & u_{j N} \\
\vdots & & & & \vdots \\
u_{J 1} & \ldots & u_{J n} & \ldots & u_{J N}
\end{array}\right]
$$


The $J \times J$ covariance matrix, $\boldsymbol{A}$, can be defined from the matrix equation

$$
\boldsymbol{A}=\boldsymbol{U} \boldsymbol{U}^{\mathrm{T}},
$$

where $\boldsymbol{U}^{T}$ is the transpose of $\boldsymbol{U}$. $\boldsymbol{A}$ has a total of $J$ eigensolutions of the form

$$
\left(\boldsymbol{A}-\lambda_{i} \boldsymbol{I}\right) e_{i}=0, \quad i=1 \ldots J,
$$

where $\boldsymbol{I}$ is a $J \times J$ identity matrix, and $\lambda_{i}$ is the ith eigenvalue (a scalar) and $\boldsymbol{e}_{i}$ is the ith eigenvector with $J$ elements $\left[e_{i 1}, \ldots, e_{i J}\right]$.

In the presentation given here, the $\boldsymbol{e}_{i}$ are scaled so that the variance in each mode is $\sum_{j=1}^{J} e_{i j}^{2}=\lambda_{i}$, in order that the magnitude of the total and baroclinic modes appear comparable.
Each $\boldsymbol{e}_{i}$ can be multiplied by a time series $\phi_{i}(n)$, the relative magnitude of mode $i$, and at time $n$ the current from an original time series, say $u_{1 n}$, may be reconstructed directly from the sum of the appropriate elements of all the eigenvectors, i.e.

$$
u_{1 n}=\sum_{i=1}^{J} \phi_{i}(n) e_{i 1}
$$

In Fig. 6 the amplitude of the eigenvectors is $\phi_{i}(n)=1$.

In common language, $\boldsymbol{e}_{1}$ is the first mode and it can be shown that the proportion of the total variance, or energy, associated with that mode (Table 3 ) is given from the eigenvalues by

$$
a_{1}=\lambda_{1} / \sum_{i=1}^{J} \lambda_{i}
$$

